\title{
El Derecho Laboral frente al contexto de crisis sanitaria mundial
}

\section{Wilfredo Alberto Sanguineti Raymond ${ }^{[*]}$}

\section{- ¿Considera Usted que el ordenamiento la- boral en los países latinoamericanos y eu- ropeos estaban preparados para afrontar una situación de crisis como la que genera la pandemia mundial a consecuencia de la propagación del coronavirus?}

Los ordenamientos laborales ni en Europa ni en América Latina cuentan con instrumentos para afrontar una situación tan excepcional como esta. Por eso entiendo que, lo que se podría valorar es mas bien si los instrumentos existentes -aunque pensados para atender situaciones distintas - resultan ser suficientes y de utilidad para encarar las nuevas necesidades generadas a raíz de la crisis sanitaria. Esto en un orden de prelación: en primer lugar, las que se encuentran en relación a la protección de la salud de los trabajadores, en segundo lugar, el tema de evitar el contacto físico observando la afectación mínima posible al empleo y; en tercer lugar, las vinculadas a garantizar una renta de sustitución para quienes no puedan trabajar por haber contraído la enfermedad o bien por las medidas de aislamiento social que lo impidan.

El balance de la aptitud y la suficiencia de instrumentos existentes para sobreponerse a estas tres necesidades puede variar según cada país - por supuesto- pero, en general, en todos los casos fue necesario adoptar medidas excepcionales para adaptarse, en razón a que tanto estos instrumentos como la regulación resultaron insuficientes. Por tanto, se tuvo que expedir una suerte de regulación excepcional, una especie de derecho del trabajo transitorio de la emergencia sanitaria.

[*] Abogado por la Pontificia Universidad Católica del Perú (PUCP). Doctor en Derecho por la Universidad de Salamanca, Catedrático de Derecho del Trabajo y de la Seguridad Social en la misma a nivel de grado, máster y doctorado. Es Director del Departamento de Derecho de Trabajo y Trabajo Social de esta Universidad y del Máster Universitario en Derecho del Trabajo y Relaciones Laborales. Conferencista internacional, conciliador-mediador del Servicio de Relaciones Laborales de Castilla y León (SERLA) entre 2003 y 2011. Autor de más de ochenta artículos aparecidos en libros y revistas españolas, europeas y americanas, autor de obras.Contacto: wsr@usal.es 
- ¿Cómo afecta la pandemia mundial originada por el COVID-19 a las relaciones laborales en Europa y América latina?

En principio, la afectación de las relaciones laborales es similar. Un virus de fácil propagación se extiende sin que contemos con una vacuna, un tratamiento o un nivel de inmunidad colectiva suficiente. En este contexto, la única manera de disminuir cifras de contagio es reduciendo el contacto social entre las personas, es decir, confinando a la población. Considerando que el trabajo constituye la principal actividad de un sector mayoritario en sociedad, el aislamiento junto a la adopción de una serie de medidas de carácter instrumental, claramente, afecta al trabajo. En este escenario se genera un triple resultado: i) en primer lugar, la paralización forzada impuesta normativamente de las actividades con mayor contacto social, ii) en segundo lugar, el traslado al domicilio de actividades desmaterializadas, es decir, aquellas que no requieren la presencia en el centro de trabajo o que pueden realizarse de manera remota - aquí cabe mencionar la incidencia de lo digital en la labor vinculada al manejo de información-, aunque no sea de manera idéntica a la realizada presencialmente y; c) en tercer lugar, demás actividades que no requieran contacto masivo y estén, igualmente, rodeadas de medidas especiales de protección como la distancia de seguridad, el uso de mascarilla y el vestir trajes.

El trabajo del personal de salud y efectivos policiales no puede parar, incluso otras actividades como la de carácter industrial. Al respecto, en España estas se paralizaron, lo que se denominó "la hibernación de la economía", pero solamente por dos semanas en las que se impuso un permiso obligatorio retribuido y recuperable, vale decir, los trabajadores se quedaban en casa y se les pagaba esas horas de manera obligatoria, pero sujetándose a su recuperación. Entonces, hay países que han optado por un cierre total de todo tipo de actividades (incluida la industria y la construcción) y otros no. Actualmente, en España, las labores relacionadas al campo de construcción y las industriales continúan; otra cosa es que la necesidad de respetar medidas de seguridad y la reducción de la demanda hagan que el volumen de trabajo baje.

Todo esto tiene este triple resultado: paralización de actividades, traslación de mayor contacto social, traslación al domicilio de lo desmaterializado y, a su vez, ello repercute en consecuencias sociales y económicas muy relevantes; por ejemplo, la falta de rentas de trabajo, trasformación de la actividad a un contexto no presencial (en el domicilio) y la reducción de la producción; por tanto, una eventual crisis económica no resultaría descartada.

\section{- ¿Considera que las relaciones laborales deben adaptarse al contexto del aisla- miento social y cuáles cree que serían los mecanismos adoptados?}

Sobre la adaptación, la única forma es enviar el trabajo a la casa para realizarlo por medios telemáticos o no y por eso se ha impuesto la medida de obligatoriedad del trabajo a distancia desde el domicilio del trabajador, siempre que sea posible, en la mayor parte de ordenamientos. De ahí que se ha producido una imposición precipitada y forzosa del teletrabajo o el trabajo desde casa; no se ha dado tiempo a regularla casi o establecer garantías y menos a respetar la voluntariedad que es un principio fundamental tanto del teletrabajo como de la propia garantía del uso del domicilio. Es decir, hay más derechos implicados, a mí no me pueden obligar a poner a disposición mi domicilio para el desarrollo del trabajo si yo no quiero, pero aquí la salud pública — como valor- ha servido para que esa ponderación se incline en esa dirección, entonces millones de trabajadores en el mundo —incluidos Perú y Españahan trasladado el trabajo a su casa. El problema que plantea esto es que se trata de una "huida precipitada”, sin garantías hacia el teletrabajo donde las personas que teletrabajan o hacen trabajo remoto, lo hacen sin previo acondicionamiento de espacio y medios; donde se pone a disposición su conexión personal del trabajo, 
sin ningún tipo de medida de seguridad o garantía, conectándose a todas horas a través de sistemas gratuitos o muy simples, no a través de redes privadas de las empresas (esto pasa solo en empresas grandes nada mas), a través de conexiones públicas (Skype, Zoom, Google Meet). Plataformas con las que recién interactúan y en las que integran reuniones que no siempre terminan siendo funcionales u operativas, mientras reciben una cantidad incesante de correos electrónicos de WhatsApp que empieza a primera hora y no acaba hasta el final del día; de tal manera que las personas se pasan el día entero estresadas, intentado trabajar y se obtiene (al final) un rendimiento incluso muy inferior al normal.

Esto no puede ser el modelo del teletrabajo del futuro, aquí se observan tres riesgos por lo menos: i) el teletrabajo impuesto sin adaptación del lugar de trabajo, sin dotación de medios y sin ningún tipo de protección de la seguridad del trabajador, ii) la colonización del domicilio del trabajador —el espacio más privado garantizado por la Constitución-, de su vida privada y de su tiempo entero, lo que deviene en la ausencia de delimitación entre el trabajo y la vida personal-familiar; y iii) el aislamiento absoluto, la falta de contacto con los demás integrantes del ambiente de interacción.

Entonces necesitamos una nueva regulación del teletrabajo por si esta situación perdurase mucho tiempo y más todavía si se proyectara hacia el futuro, pero no para brindarle más facilidades a los empleadores y así esta modalidad acabe con las garantías que ahora existen, aunque no se apliquen sino excepcionalmente; vale decir otorgar más garantías. Por ejemplo, que al trabajador se le dote de los equipos, se acondicione su domicilio, su puesto de trabajo, se cubran los gastos incluso que se compense el uso permanente del domicilio en mérito a que se denota el empleo de un espacio del hogar para dedicarlo, permanentemente, a costa del trabajador; ahorrándose un concepto de pago y exigiéndose cumplir con una carga que a este no corresponde.
Además, debe garantizarse la flexibilidad al usar el tiempo del trabajo evitando conducir al trabajador hacia el incumplimiento de las normas sobre delimitación de la jornada laboral; de manera que los teletrabajadores dispongan de un rango de horas determinado. Medir el cumplimiento de la regla sobre jornada no es imposible, tecnológicamente, se puede considerar el tiempo de conexión a través de un programa informático o a través del cálculo destinado al alcance de los objetivos encargados. En tercer lugar, hay que limitar el control del trabajador a lo estrictamente necesario para vigilar que se cumplan sus obligaciones laborales, con respeto de sus derechos fundamentales. En cuanto a la intimidad del trabajador, no se utilice por tanto ni la videovigilancia ni la grabación de sonidos, si no hay otra manera de controlar a través del programa informático y aun así cuidando que datos se recogen y para que se utilizan, estos deben ser los necesarios y usarse solo para el control.

Luego, hay que garantizar el derecho a la desconexión digital que más allá de los espacios de desarrollo del trabajo vinculados con esa jornada, no pueda ser el trabajador bombardeado no ya solo por órdenes extemporáneas sino por comunicaciones de compañeros, pedidos de clientes, requerimientos de información, mensajes de los alumnos lo que fuera que terminan por generar una situación de absoluta dependencia del trabajador, de invasión del espacio del trabajador, derecho a la desconexión digital.

Finalmente, la posibilidad de alternancia es una cosa que hay que garantizar o sea evitar el aislamiento exige prever que el teletrabajo que va perdurar donde perdure una alternancia entre trabajo en casa y otros en el centro del trabajo, no todo tiempo fuera. El contacto social y personal es importante: el contacto con los jefes, con los compañeros, con los clientes, con los alumnos que uno tiene. Ese es el tipo de teletrabajo que va a funcionar y que tiene sentido, en alternancia, no el teletrabajo totalmente externo donde no exista una opción ge- 
neralizada que sirva para todos. Hay que tener en cuenta, además que todo esto debe ser con respeto fundamental del reconocimiento de la existencia de una relación laboral, porque ahora los teletrabajadores que trabajan desde casa tenían uno antes, pero ¿Qué va a pasar cuando después se quiera, por ejemplo, contratar a alguien? Se le puede decir que al resultar difícil el control del trabajo en casa, simplemente haga lo que el empleador le indique y, por ello, le pague. Esto puede dar lugar a una "uberizacion de los trabajos" vinculados con la información, muy peligrosa. Tendremos una suerte de riders, nuevos trabajadores sobreexplotados que reparten productos y eso no tiene ningún sentido puesto que la laboralidad cuando hay dependencia, cuando verdaderamente hay una disponibilidad del trabajo del trabajador por el empleador, debe ser garantizada.

\section{- ¿Cuál debería ser el rol del empleador y del Estado ante la crisis económica pro- ducida por la pandemia mundial ante la propagación del COVID-19?}

El empleador se ve afectado por una situación como esta que le impide producir, en muchos casos, debido a una prohibición legal al desarrollo de sus actividades, ve alterada su dinámica porque ahora tiene que recibir la prestación del trabajador realizada desde su casa o porque se reduce la demanda de determinados productos. Es decir, las clínicas dentales pueden funcionar, pero durante toda la primera etapa no ha ido nadie, por ejemplo. Entonces estas son causas de fuerza mayor - en algún caso la prohibición legal también cuando se enferma la mayoría de trabajadores y tiene que parar- o son causas económicas que habilitan a suspender los contratos de trabajo o a continuarlos por medios virtuales desde el domicilio, pero por tanto no a extinguir los contratos de trabajo.

Ante ello, la primera responsabilidad del empleador es obrar en consecuencia y actuar preservando el empleo, respetando las normas; segundo lugar, adaptándose al trabajo a distancia y, en tercer lugar, dotando medidas de protección a los trabajadores que laboren en las actividades esenciales o las no paralizadas, puesto que ahí el empleador tiene que ser garante de la protección. Para mi ese es el rol del empleador que no difiere de su rol normal pero que tiene unas particularidades en este caso.

En cuanto al Estado creo que debería intervenir en varios sentidos: i) adoptando medidas de protección del empleo que limiten los despidos por una causa temporal, cuestión prevista con carácter general en los ordenamientos que tienen una regulación causal de la extinción del contrato de trabajo. Sobre todo, el rol estatal es de aportar rentas de sustitución a los trabajadores con contrato suspendido, esta es una responsabilidad competente al Estado o al empleador que en principio, no recibe la prestación ¿Por qué vías es factible? Bueno, el Estado a través de la protección por del desempleo —existente en muchos países de América Latina - o mediante prestaciones extraordinarias para los trabajadores provenientes del Estado. No creo que tenga sentido que, para soportar esas situaciones de suspensión del contrato de trabajo, el trabajador tenga que sacrificar ni sus vacaciones ni las cantidades que percibe, la compensación por tiempos de servicios y menos todavía los fondos de pensiones; este es un costo que no tiene por qué pagar el trabajador, sino que lo debe pagar la sociedad entera. Claro no me parece que sea exigible que la población se quede en la casa sin esas rentas, este es un gran problema de países donde no se ha constituido un estado social donde prima un alto grado de informalidad ¿Cómo uno puede pedirles a las personas que no salgan a la calle, si no hay ningún tipo de forma ni ningún mecanismo de protección frente al desempleo temporal o frente a la ausencia de rentas derivadas del trabajo independiente o autónomo? y se les prohíbe salir. Esto no es exigible, el Estado debe cubrir estas situaciones.

Los años buenos del 2000 y 2020 , en América Latina y en especial en el Perú, debieron usarse para construir un estado social, 
crear estos mecanismos de protección social y no se ha hecho. Ahora la gente tiene que salir a ganarse la vida y por eso la curva de contagios no disminuye como ha disminuido en España donde la gente se ha quedado en su casa, porque ha habido una renta de sustitución, entonces donde esta se ausente, la gente no tiene más remedio que salir. Esa omisión de construir un estado de social, de haber construido mecanismos o haber suplido por alguna vía está saliendo bastante cara a varios países; como el Perú - que llevan tres meses paralizados- y la curva de contagio no se aplana, ¿a donde vamos a llegar? Se está casi volviendo a la situación de partida sin reducir la curva de contagios, ¿para qué tenemos esas reservas internacionales si no hay tejido social, no hay mecanismos de integración social que permitan que ese dinero llegue a las personas? No hay forma, lamentablemente.

\section{- ¿Qué mecanismos existen en la Unión Eu- ropea y, particularmente, en España para proteger al trabajador y la fuente de em- pleo de la pandemia mundial generada por la propagación del COVID-19?}

En todos los países de Europa se han adoptado estrategias similares dirigidas, por un lado, a favorecer las fórmulas de suspensión colectiva de los contratos de trabajo frente a los despidos o extinciones contractuales a través de un mecanismo que, en España, se llama expediente de regulación temporal de empleo y, en segundo lugar, imponer un mecanismo de teletrabajo siempre que esta sea posible. Todo esto unido a mecanismos de soporte, las rentas de sustitución para los trabajadores como he indicado especialmente, mediante sistemas de protección por desempleo que se han adaptado, se ha facilitado su acceso, incluso para las personas que no habían cumplido con los requisitos; esos sistemas se han perfeccionado y se han creado otros sistemas alternativos que no existían como una prestación específica para trabajadores del hogar o por cese de actividades de los trabajado- res autónomos que tampoco existía. La renta por sustitución es un elemento clave.

Otra pieza clave viene acompañada de un intento de facilitar la tramitación de los expedientes de regulación de empleo y reducir los costos a los empresarios -en España - aun cuando con el contrato esté suspendido, el empleador tiene que seguir pagando cuotas de salario bruto. Cuando ello se debe a un motivo de fuerza mayor, estas cotizaciones no hay que abonarlas de manera que se reduce el costo a las empresas ya que estas viven una situación difícil. Esto tiene costo económico muy elevado, pero es uno que hay que afrontar para preservar el tejido social y productivo durante esta crisis y permitir, luego, una recuperación mejor y más rápida.

\section{¿Existe algún convenio de la OIT que haya analizado o tratado una situación similar a la que experimentamos a consecuencia de la pandemia mundial?}

Los convenios de la OIT no están previstos para situaciones tan excepcionales como esta, si no para situaciones ordinarias $y$, por tanto, no contemplan una situación que no se ha presentado en los 100 años de existencia de esta organización. La última pandemia data de 1918, empezó y terminó en 1919, cuando se funda la OIT y desde entonces no hemos tenido nada similar. Si bien es cierto que hay alguna referencia a situaciones próximas, por ejemplo, en el Convenio sobre Trabajo Forzoso o en la Recomendación 200 de 2010 sobre el VIH y el SIDA, pero la perspectiva no es la misma. Por lo que, ahora no se pueden extraer materiales que puedan servir.

\section{- ¿Cuáles creen que serían los mecanismos políticos y legislativos adecuados para su- perar la crisis económica y poder preservar el empleo en los países de América Latina? \\ El problema es que la paralización de ac- tividades generará un decrecimiento del Pro- ducto Bruto Interno y no sabemos con qué}


velocidad s e va a recuperar ¿Qué elementos nos pueden ser útiles para afrontar esta situación que, con mayor o menor intensidad, se va a presentar las dificultades económicas? El primer elemento - para mí- es la concertación social y política, es decir, la búsqueda de objetivos nacionales y puntos de consenso entre las fuerzas políticas y participación de los interesados (trabajadores y empleadores), es una cuestión fundamental de método. En cuanto a los temas de fondo, un segundo elemento es la recuperación del rol del Estado en el impulso de la recuperación económica, harán falta políticas keynesianas que cuestan mucho a los sectores formados en la ortodoxia económica adoptar pero que si, en un momento pueden relevar su utilidad, es precisamente en este. Vale decir que el Estado va a tener que gastar, tanto en protección social como en actividades que promuevan una recuperación del tono del funcionamiento de la economía. El tercer elemento es una garantía solida del empleo, o sea políticas legislativas que garanticen la conservación del empleo, que limite los despidos sin causa, pero a la vez apoyen a las empresas a mantener puestos de trabajo, y que promuevan su formalización.

Las instituciones clásicas del derecho del trabajo son fundamentales, no solo para enfrentar la pandemia sino para la recuperación. Contar con un contrato de trabajo formal, re- conocido como tal, es un elemento clave para garantizar la protección del empleo y el acceso a la protección social de ser necesario. La causalidad de la contratación temporal o la del despido y la preferencia por los mecanismos de suspensión del contrato de trabajo frente a los mecanismos de extinción son herramientas fundamentales, es decir, no hay nada en la situación de dificultad económica que aconseje desmontar el ordenamiento laboral. Si hay que construir mecanismos que favorezcan la adaptabilidad de este a la dinámica económica, pero partiendo de que, en principio, los supuestos de extinción del contrato de trabajo deben producirse cuando efectivamente existe una causa que la justifique.

Entonces la crisis abre desde mi punto de vista un espacio para la relegitimación del ordenamiento laboral y no a la inversa, ahora está claro que el ordenamiento laboral no es el responsable de la crisis, no está en su origen ni ha contribuido a agravarla. Mas bien, este ha contribuido y está contribuyendo a paliar esa crisis porque prevé el teletrabajo, el mecanismo de la suspensión del contrato de trabajo que impide que las empresas echen a todo el personal por la suspensión de actividades. Estos mecanismos son una garantía que hay que preservar, legitimarlos y no al contrario. A partir de la crisis económica no hay que precarizar las relaciones laborales, no es necesario, al contrario, genera más desigualdad y más pobreza. 